\title{
Monetary Policy in Deflation: The Liquidity Trap in History and Practice
}

\author{
Athanasios Orphanides* \\ Board of Governors of the Federal Reserve System
}

December 2003

\begin{abstract}
The experience of the U.S. economy during the mid-1930s, when short-term nominal interest rates were continuously close to zero, is sometimes taken as evidence that monetary policy was ineffective and the economy was in a "liquidity trap." Close examination of the historical policy record for the period indicates that the evidence does not support such assertions. The incomplete and erratic recovery from the Great Depression can be traced to a failure to pursue consistently expansionary policy resulting from an incorrect understanding of monetary policy in an environment of very low short-term nominal interest rates. Commonalities with the Japanese experience during the late 1990s, and the inadequacy of short-term interest rates as indicators of the stance of monetary policy are discussed and a robust operating procedure for implementing monetary policy in a low interest rate environment by adjusting the maturity of targeted interest rate instruments is described.
\end{abstract}

KEywords: Zero interest-rate bound, liquidity trap, great depression, Japan.

JEL Classification System: E31, E52, E58.

Correspondence: Federal Reserve Board, Washington, D.C. 20551, phone: (202) 452-2654, e-mail: Athanasios.Orphanides@frb.gov.

*I would like to thank Mike Bordo, Charalambos Christofides, Ed Ettin, Takeshi Kimura, Allan Meltzer, Weshah Razzak, Marc Weidenmier and participants at presentations at the European Central Bank and Claremont-McKenna College for helpful discussions and comments. The opinions expressed are those of the author and do not necessarily reflect views of the Board of Governors of the Federal Reserve System. 


\section{Introduction}

Writing in 1930, a few months into the "slump" we now know as the Great Depression, John Maynard Keynes expressed concern that the monetary policy action necessary to restore prosperity might not be forthcoming: "I repeat that the greatest evil of the moment and the greatest danger to economic progress in the near future are to be found in the unwillingness of the Central Banks of the world to allow the market-rate of interest to fall fast enough" (1930, p. 207). Anticipating a subsequent debate, Keynes provided a careful analysis of possible practical limits to expansionary monetary policy in a slumpwhat would later be called a "liquidity trap." He dismissed the notion that monetary policy would become ineffective during a slump - provided policymakers were willing to take deliberate and vigorous action towards restoring prosperity: "Yet who can reasonably doubt the ultimate outcome [a lasting recovery] — unless the obstinate maintenance of misguided monetary policies is going to continue to sap the foundations of capitalist society?" (p. 384). Even without any real constraints on the ability of a central bank to take expansionary action, however, Keynes recognized that "the mentality and ideas" of the policymakers themselves could stand in the way of the necessary policies. His words revealed less than full confidence that the appropriate policies would be pursued: "It has been my role for the last eleven years to play the part of Cassandra ... I hope that it may not be so on this occasion" (p. 385). Subsequent events, unfortunately, proved that Keynes was still captive of Apollo's wicked curse.

In the United States, Federal Reserve policy during the 1930s is widely recognized as a dramatic failure. But it took many decades for Federal Reserve officials to accept responsibility for that failure, and, more generally, it took considerable debate and over a long period of time for economists and historians to reach substantial agreement on the harm that monetary policy caused during the 1930s. While some (including Keynes himself) had little doubt regarding the unhelpful role of monetary policy, others (including, many "Keynesians") concentrated instead on other factors, including the role of fiscal policy, especially after Keynes (1936) highlighted its potential for fighting the slump. ${ }^{1}$ The tale

\footnotetext{
${ }^{1}$ See Leijonhufvud (1968) for a discussion of this and other differences between the economics of Keynes
} 
of the "ineffectiveness" of monetary policy to inflate the economy from a slump provided a convenient alternative explanation of events that also afforded a much less negative view of the role of monetary policy during that episode.

With inflation becoming the norm in the industrialized world following World War II, monetary policy in a deflationary environment largely remained the subject of historical inquiries. But the liquidity trap debate re-emerged in relation to developments during the 1990s in Japan, and more recently, and largely based on concerns stemming from the recent Japanese experience, in relation to the possibility of deflation in other industrialized economies. Importantly, while the Japanese economy of the 1990s has not been through a catastrophe of a magnitude similar to that experienced in the U.S. economy of the 1930s, some uncomfortable similarities, especially regarding the possible role of monetary policy action or inaction in this experience, have not escaped attention. ${ }^{2}$

In light of this experience, in this paper I revisit some of the relevant historical experience associated with the liquidity trap debate, to reexamine one aspect of the specific question suggested by Keynes in 1930: Is the liquidity trap an inescapable reality of modern capitalist economies, or is its appearance merely an artifact of "misguided monetary policies" reflecting the "unwillingness" to adopt adequate monetary policy action? The question is important for it points to the related issue of a possible self-induced-policy trap of considerable practical importance. If the liquidity trap does not reflect a real difficulty but only a perceived problem reflecting "the mentality and ideas" of policymakers, could such a perception in itself be self-fulfilling?

To investigate these questions, I focus first on an historical analysis of events surrounding a specific episode during the 1930s in the United States - the recession of 1937-38. In particular, drawing from the extensive historical policy record available for the period I illustrate how this episode can provide some information relevant for identifying the role of

and what later became associated with Keynesian economics. See Friedman and Schwartz (1963) and Temin (1976) for the classic monetarist and Keynesian interpretations of the Great Depression, respectively.

${ }^{2}$ The role of monetary policy in Japan and/or comparisons with the U.S. experience during the Great Depression has been examined by numerous studies in recent years, including Ahearne et al (2002), Bernanke (2000), Coenen and Wieland (2003), Kuttner and Posen (2001), Krugman (1998, 2000), McCallum (2000), Meltzer (1999), Okina (1999), Orphanides and Wieland (1998, 2000), Reifschneider and Williams (2000), and Svensson (2001). 
"the mentality and ideas" of policymakers in inducing an appearance of a liquidity trap.

The validity of the interpretation of the experience of the mid-1930s as one in which monetary policy was ineffective rests on the hypothesis that the Federal Reserve actively pursued expansionary policy during this period and that, despite such efforts, the economy failed to expand and prices failed to rise. I argue that the historical monetary policy record is not consistent with this hypothesis. Rather, the evidence suggests that the Federal Reserve did not pursue a consistently expansionary policy. The record points to Federal Reserve unwillingness to pursue sufficient monetary expansion during much of this period and suggests that monetary policy actions remained effective. An incorrect understanding of the economy and flawed policy, rather than monetary policy ineffectiveness, appear to have been behind the dismal outcomes of the period. Indeed, the record confirms that Keynes' concerns regarding the role of "the mentality and ideas" of policymakers for the adverse macroeconomic outcomes that followed was right on the mark.

With the analysis of the 1930s experience in the United States serving as background, I also discuss some commonalities with the recent experience with near-zero interest rates in Japan. Key to a better understanding of incorrect assessments of monetary policy in a low interest rate environment is the inadequacy of the short-term rate of interest as an indicator of the stance of monetary policy under such circumstances. A central bank facing an apparent liquidity trap can adopt robust operating procedures for implementing monetary policy in a low interest rate environment by adjusting the maturity of targeted interest rate instruments. Drawing on the recent Japanese experience as an example, I describe how such a procedure may be phased in as a natural extension of an operating procedure that targets the overnight interest rate, under normal circumstances.

\section{A Liquidity Trap during the 1930s?}

As Brunner and Meltzer (1968) noted in their seminal analysis of liquidity traps: "Few conclusions about economic events have been repeated as frequently or have had as much influence on economists's attitudes toward monetary policy as the assertion that the monetary system of the thirties was 'caught in a liquidity trap' " (p. 1). The primary reason for 
the popularity of the liquidity trap tale can be seen in the path of short-term interest rates presented in Figure 1. Following the onset of the Great Depression, short-term interest rates generally fell (albeit not quickly enough, in light of the deflationary situation) and by the end of the Great Depression in 1932 were very close to zero. Indeed, from 1932 on, and for more than a decade, short-term interest rates remained very close to zero continuously. Given the usual practice of associating monetary policy with movements in short-term rates of interest, then, a natural interpretation could be that after 1932, monetary policy had reached its limit in the sense that it could no longer materially reduce the short-term rate of interest. By this reasoning, the behavior of the economy during this period was not and could not have been influenced by Federal Reserve actions. Indeed, this is the essence of the evidence taken to imply that the U.S. economy during the 1930s was stuck in a liquidity trap. But did the prevalence of a consistently low short-term rate of interest indicate that additional monetary expansion would have been ineffective, if the Federal Reserve had opted to pursue additional monetary expansion, or even that the Federal Reserve was constrained from pursuing such additional monetary expansion?

The events surrounding the recession of 1937-38 in the United States provide an informative case study for examining these issues. Using the usual metric of the short-run rate of interest shown in Figure 1, hardly a blip registers that might indicate any possible role for monetary policy during that episode - under the usual mapping of short-term interest rates to monetary policy described above. As a closer examination of that episode suggests, however, the small blip in interest rates that can be seen in 1937, reflected a significant and deliberate tightening of monetary policy in the United States at the time and, as such an informative natural experiment for assessing the role and effectiveness of monetary policy at near-zero interest rates.

To set the stage we need to start our analysis somewhat earlier in time, during the slow recovery from the Great Depression in 1934-35. ${ }^{3}$ As Meltzer (2003) explains, Federal Reserve policy was rather passive during this period. Industrial production and employment were slowly recovering from the depth of the Depression, and prices both of goods and of

\footnotetext{
${ }^{3}$ For details regarding events and relevant policy decisions earlier during the 1930s I refer the reader to the classic expositions in Friedman and Schwartz (1963) and Meltzer (2003).
} 
assets were also slowly rising somewhat but also remained far below their pre-Depression levels. (Figures 2 and 3). The consensus views at the Federal Reserve as to the role of monetary policy were usefully summarized in a response to a question by Representative Brown to Governor (and later Chairman) Eccles on March 4, 1935, during the Hearings for the Banking Act of $1935:^{4}$

Mr. Brown. ... I think it would be interesting to Members of Congress, and particularly to this committee, to know what your policy would be under present conditions ... what you would do if given this power under present conditions[.]

Governor Eccles. ... Under present circumstances there is very little, if anything, that can be done.

Mr. Goldsborough. You mean you cannot push a string.

Governor Eccles. That is a good way to put it, one cannot push a string. We are in the depths of a depression and, as I have said several times before this committee, beyond creating an easy money situation through reduction of discount rates and through the creation of excess reserves, there is little, if anything that the reserve organization can do toward bringing about recovery. I believe that in a condition of great business activity that is developing to a point of credit inflation monetary action can very effectively curb undue expansion. [sic] (United States Congress, 1935, p. 376)

Federal Reserve policy was perceived to be at its limit regarding the degree of accommodation it could provide for business expansion but policymakers, cognizant of the possibility of excessive credit creation, should be ready to act against the resulting inflation threat in that case. In the background, of course, was fear of a repetition of the perceived excesses of 1929 that were believed to have been the cause of the Great Depression. Throughout the 1930s, the Federal Reserve kept fighting the ghosts of the lost battle of 1929 .

With short-term interest rates near zero, the banking system maintained a level of excess reserves which the Federal Reserve monitored closely. During 1934 and 1935, however, an external force was to come into play. Gold inflows from Europe slowly but steadily expanded

\footnotetext{
${ }^{4}$ The Act, which was passed, effectively shifted control of Federal Reserve policy to the Board of Governors, thus creating an independent central bank. Representative Brown was asking whether policy would be materially different under the new legislation relative to the law in place at the time. As noted by Meltzer (2003), this exchange also gave rise to the famous "pushing on a string" description of monetary policy at the time.
} 
the U.S. money supply, and the Federal Reserve faced a situation of an increasing level of excess reserves in the banking system. Thus, despite Federal Reserve passivity, monetary policy was fortuitously becoming increasingly more expansionary during this period, thereby facilitating the recovery. But surely, given their potential for generating inflation, these fortuitous developments could not be allowed to continue. By December, 1935, Federal Reserve staff expressed its serious concerns regarding the situation as follows:

There is the general fear which many people entertain that excess reserves of the present magnitude must sooner or later set in motion inflationary forces which, if not dealt with before they get strongly under way, may prove impossible to control. (Federal Reserve Staff Memorandum, December 1935)

The Minutes of the December 1935 FOMC meeting indicate a heated discussion as to whether the Federal Reserve should take some action to contain this potential threat. Governor Martin expressed strong reservations:

In any action taken at the present time there is too great danger of discouraging efforts towards recovery; in fact the danger of retarding recovery is too great to take the risk of any action not more clearly indicated than at the present time, whether it be a sale or run-off of Governments or the increase of reserve requirements. (Governor Martin, December 1935 FOMC meeting.)

Whether it was due to such opposition from a vocal minority or for other reasons is unclear from the Minutes; regardless, the decision on a possible tightening action, and if so, the type of tightening action was postponed. With continued gold inflows in 1936, concerns regarding their inflationary potential intensified and "the gold problem" occupied center stage at policy discussions. Unfortunately, a crucial voice of reason on the committee on the issue, now-President Martin, would not be allowed to participate at FOMC meetings that year. ${ }^{5}$ Within a few months, the Federal Reserve was to set in motion a series of policy tightenings in the form of increases in reserve requirements.

\footnotetext{
${ }^{5}$ Under the new legislation, Chicago and St. Louis were paired together for one voting seat on the Committee and, importantly, it was decided that non-voting members would not be allowed to participate at the meetings so only one of these two Presidents could be present at the FOMC meetings that year. The Chicago and St Louis Boards of Directors both nominated the Presidents of their respective Banks to represent the two districts at the FOMC and were unable to resolve their disagreement in repeated attempts. The issue remained unresolved even after the first meeting of the new FOMC and the two districts had no representation at that meeting. On May 13, 1936, a joint subcommittee of the Boards of the two Banks agreed that the two banks would rotate representation. The agreement called for Chicago to have the choice
} 
The first increase in reserve requirements was announced on July 14, 1936. A press release made two basic points. First, it was argued that this policy action was not a tightening:

This action eliminates as a basis of possible injurious credit expansion a part of the excess reserves ... These excess reserves have resulted almost entirely from the inflow of gold from abroad and not from the System's policy of encouraging full recovery through the creation and maintenance of easy money conditions. The easy money policy remains unchanged and will be continued. ...

The part of excess reserves thus eliminated is superfluous for all present or prospective needs of commerce, industry, and agriculture and can be absorbed at this time without affecting money rates and without restrictive influence upon member banks ...

And second, it was suggested that this was an "opportune" time for this action, implying that further delay could be deleterious to the economy:

The present is an opportune time for the adoption of such a measure. While there is now no excessive credit expansion, since the excess reserves have not been utilized, later action when some member banks may have expanded their loans and investments and utilized their excess reserves might involve the risk of bringing about a severe liquidation and of starting a deflationary cycle. It is far better to sterilize a part of these superfluous reserves while they are still unused than to permit a credit structure to be erected upon them and then to to withdraw the foundation of the structure."

Despite the 1936 increase in reserve requirements, with the continuing inflow of gold excess reserves stayed quite high, indeed above their level in early 1935 even after this first tightening round (Figure 4). The economy continued to grow further (Figure 2), with industrial production in 1936 reaching (for the first time) the "dangerous" levels it had reached before the 1929 collapse. Although unemployment remained high, by the end of the year the potentially inflationary threat was perceived as unacceptably high and in January 1937 the Federal Reserve acted to raise reserve requirements again, to the maximum possible

for either 1936 or 1937 and Chicago decided to go first. This description of events, which set the precedent for rotation of FOMC representation among different districts, is based on the Minutes of the FRB St. Louis and Chicago Banks. I wish to thank Robert Rasche for his help in digging through the FRB St. Louis Minutes and Tina Lam for checking the corresponding FRB Chicago Minutes for this information. 
extent within its powers. There was substantial consensus (though not unanimity) for this action, including by the staff policy advisors. The staff position and recommendation were reflected in the analysis offered by Emanuel Goldenweiser and John H. Williams at the January 26, 1937 FOMC meeting. ${ }^{6}$

[Mr. Goldenweiser] discussed the present volume of industrial production and employment and other indications that recovery was well advanced ... and said that the principal reasons for doubt as to whether action should be taken at this time were the continued volume of unemployment and labor troubles now and in prospect.

He then expressed the opinion that the most effective time for action to prevent the development of unsound and speculative situations is in the early stages of such a movement ...

... as short-term rates had been abnormally low in relation to long-term rates and some stiffening of the former would be desirable, action to absorb excess reserves should be taken at this time.

... an increase in reserve requirement by $331 / 3 \%$ at this time would not involve a great risk on the part of the Federal Reserve System ... and would restore the System to the position in relation to the market which it normally should occupy. ...

Mr Williams had stated that he felt the business and economic situation in the United States reached what might be regarded in a general way as normal and that there were some indications that in certain respects it was going beyond normal. ...

Mr Williams concluded with the statement that it appeared that there was every argument for early action by the System, that he felt that the Board should increase reserve requirements to the limit of its authority, and that this would place the System in a position to deal effectively with the problems which would arise later in connection with the control of credit through the medium of open market operations." (FOMC Minutes, January 26, 1937)

Three elements are especially noteworthy in this analysis: First, the explicit reference by Goldenweiser to "abnormally low" interest rates and preference for "some stiffening."

\footnotetext{
${ }^{6}$ Goldenweiser was Director of the Research and Statistics Division and the economist of the FOMC, the highest ranking staff member at the Board in Washington. John Williams was Vice President of the Federal Reserve Bank of New York and associate economist of the FOMC. He was also a professor at Harvard University at the time. The two provided the key policy briefings at FOMC meetings during this period, including recommendations for policy action.
} 
The Federal Reserve clearly recognized that a relationship between the supply of money and interest rates (at both short and longer-term maturities) remained, despite the fact that interest rates were already very low. Second, Williams' comparison of business conditions to "normal" levels, suggesting that the Federal Reserve was attempting to map the level of real economic activity into the potential for inflation. ${ }^{7}$ In essence, Williams was arguing that the economy was operating at or near its non-inflationary potential at the time. (This, of course, suggests an incredibly pessimistic assessment of the economy's growth potential during the decade.) And third, the emphasis on the desirability of a preemptive tightening at the time (reflected in both Goldenweiser and Williams). This was not the first preemptive strike against inflation at the Federal Reserve. As noted by Orphanides (2003), by the early 1920s the Federal Reserve had already developed the tools and methods of analysis that approximates a modern Phillips-curve based approach to policy design. Some key policy decisions during the 1920s as well as this episode can be usefully examined and understood in terms of this "modern" framework as "pre-emptive strikes against inflation," based on a Phillips-curve approach.

In a press statement on January 30, the Board explained its decision for the further tightening action as follows:

The section of the law which authorizes the Board to change reserve requirements for member banks states that when this power is used it shall be 'in order to prevent injurious credit expansion or contraction.' The significance of this language is that it places responsibility on the Board to use its power to change reserve requirements not only to counteract an injurious credit expansion or contraction after it has developed, but also to anticipate and prevent such an expansion or contraction. ...

In view of all these considerations, the Board believes that the action taken at this time will operate to prevent an injurious credit expansion and at the same time give assurance for continued progress toward full recovery. (Board Press Statement, January 30, 1937)

An interesting aspect of the January tightening decision was that it was to be imple-

\footnotetext{
${ }^{7}$ The concept of "normal," was used at the time to reflect a notion of "potential" or "trend" output, in today's terminology. See Orphanides (2003) for a discussion of the early development and usage of these concepts during the 1920 s for monetary policy purposes.
} 
mented in two steps. Half of the reserve requirement increase was to take effect on March 6 and the rest on May 1. The decision followed a proposal by Governor McKee who opposed the tightening action and hoped to temper it. Splitting the increase in two parts would have given the Federal Reserve the opportunity to cancel the second installment if the tightening following the first increase proved more potent than anticipated. Indeed, following the first reduction in excess reserves in March, interest rates rose by more than was expected across both short and longer-term maturities. But the response to this adverse development was not to cancel the second part of the tightening. Rather the majority of the FOMC adopted the position that the reduction in excess reserves and associated increase in interest rates was simply not a tightening at all. Following a wave of criticisms, Chairman Eccles issued a statement on March 16, 1937 to clarify his reasoning:

I wish to correct erroneous interpretations which have been circulated with reference to my position on credit and monetary policies.

I have been and still am an advocate of an easy money policy and expect to continue to be an advocate of such a policy so long as there are large numbers of people who are unable to find employment in private industry, which means that the full productive capacity of the nation is not being fully utilized. ... An ample supply of funds at reasonable rates exists and will exist after the increased reserve requirements take full effect on May 1. (Statement of Chairman Eccles with reference to his position on credit and monetary policies for release in newspapers of March 16, 1937.)

The Chairman, further clarified his reasoning in favor of the tightening in an article published in Fortune magazine in April. Raising the specter of 1929 once again, he stressed:

Recovery is now under way, but if it were permitted to become a runaway boom it would be followed by another disastrous crash. $(1937,3$.

The adverse market reaction was discussed at the April FOMC meeting, in connection to the possible cancellation of the remaining tightening action that was to take effect on May 1. Only a small minority of Committee members were willing to acknowledge the relation between the policy tightening and the adverse interest rate reaction:

At this point a question was raised as to whether the action of the Board in increasing reserve requirements was the major cause of the unsettled condition 
in the market and all of the members, with the exception of Messrs. McKee and Davis, stated that they did not think it was the major cause... Mr. McKee felt it was the major cause and Mr. Davis felt that if not the major cause, it was the immediate cause. (FOMC Minutes, April 3, 1937)

Neither did the staff offer advice to the Committee to consider reversing the last part of the tightening action. Indeed, both Goldeweiser and Williams expressed the view that it would be unwise to do so:

[Mr Goldenweiser] expressed the further opinion that cancellation of the May 1 increase in reserve requirements ... would be equivalent to announcing that the Board had made a mistake, which he did not feel was the case ...

Mr Williams said he found difficulty in seeing any economic necessity for action at this time. He said action might be rested on the necessity for continued easy money rates but that even if there were some advances in the low rates which had obtained the new rates could not be regarded as high. He felt that in the present situation, if the causes of inflationary tendencies were not corrected, the System should possibly even follow a policy of restraint. He also expressed the feeling that with the increase in prices and business profits a proportionate increase in rates should be expected. (FOMC Minutes, April 3, 1937)

On May 1, 1937, the final leg of the tightening was completed. With that in place, excess reserves fell back to levels as low as had not been seen since several years earlier (Figure 4). May 1937 also marked the peak of the incomplete expansion from the Great Depression of 1929-1932. The economy promptly returned to recession. Though the extent of the sharp decline in activity was not immediately evident, by Fall it became fully clear to the Committee that the economy was thrown back to a severe recession, once again. The following evaluation of the situation by Williams at the November 1937 meeting is informative, both for offering a frank admission that the FOMC apparently wished for a slowdown to occur and also for outlining the case that the recession, nonetheless, had nothing to do with the monetary tightening that preceded it. Particularly enlightening is the reasoning offered by Williams as to why a reversal of the earlier tightening action would be ill advised.

We all know how it developed. There was a feeling last spring that things were going pretty fast ... we had about six months of incipient boom conditions with 
rapid rise of prices, price and wage spirals and forward buying and you will recall that last spring there were dangers of a run-away situation which would bring the recovery prematurely to a close. We all felt, as a result of that, that some recession was desirable ...

We have had continued ease of money all through the depression. We have never had a recovery like that. It follows from that that we can't count upon a policy of monetary ease as a major corrective. ...

In response to an inquiry by Mr. Davis as to how the increase in reserve requirements has been in the picture, Mr. Williams stated that it was not the cause but rather the occasion for the change. ... It is a coincidence in time. ...

If action is taken now it will be rationalized that, in the event of recovery, the action was what was needed and the System was the cause of the downturn. It makes a bad record and confused thinking. I am convinced that the thing is primarily non-monetary and I would like to see it through on that ground. There is no good reason now for a major depression and that being the case there is a good chance of a non-monetary program working out and I would rather not muddy the record with action that might be misinterpreted. (FOMC Meeting, November 29, 1937. Transcript of notes taken on the statement by Mr. Williams.)

The Federal Reserve made every effort to build a convincing case that the cause of the 1937 downturn could be more than accounted for by factors other than the monetary tightening and that policy action by the rest of the government and not by the Federal Reserve were needed to restore prosperity. "Causes of the recession," a famous essay written at the Board by Lauchlin Currie (a close advisor to Chairman Eccles) at the time offered one of the most advanced non-monetary interpretations of events of its time and dismissed the possible role of monetary policy. Currie defended the 1937 tightening as follows:

There was, as previously remarked, inflationary sentiment in the air. ...

The rise in reserve requirements was regarded as a precautionary rather than a restrictive measure. ...

The action may have contributed to the removal of the fear or expectation of monetary inflation and an indefinite rise in prices ... If so, its effect was salutary ... From this point of view, the criticism should be not that the action was taken, but rather that it was unduly delayed. (Currie 1980, 326-327.) 
In a speech on December 14, 1937, Chairman Eccles himself summarized the Federal Reserve views as follows:

There are critics who contend that monetary policy has been primarily responsible for the present recession. They think that sterilization of incoming gold by the Treasury and the actions of the Board of Governors of the Federal Reserve System in increasing the reserve requirements of member banks caused a reversal of the upward movement. Upon careful searching of the record, I cannot find convincing evidence to support this analysis. ...

If these actions taken last winter had a psychological effect in restraining the inflationary developments which were clearly under way at the time, then these actions were definitely in the public interest. If this be so then my only regret is not that the actions were taken, but that they were not taken earlier. (Address before the annual meeting of the American Farm Bureau Federation, December 14, 1937.)

Consistent with these views, the Federal Reserve did not reverse the 1937 tightening despite the continued deterioration in the economy that can be seen in Figure 2.

Federal Reserve policy remained unchanged until April 1938, when President Roosevelt asked the Board to reverse its tightening action as part of a broader economic recovery program. The program, including the reversal of the reserve requirement increase was announced by the President on April 14. The President's message also noted that the Federal Reserve Board had indicated its willingness to reduce reserve requirements, which the Board promptly saw through on April 15. Whether the Federal Reserve would have undertaken this action without the administration's prompting remains an open question. Some suggestive considerations appeared in the Minutes of the April 21, 1938 FOMC meeting (the first FOMC meeting following the Board action):

With respect to the Board's action in increasing reserve requirements, the statement was made that while, following that action, there remained a large volume of excess reserves accompanied by extremely low rates of interest and an abundance of available funds, many people were under the impression that the Board's action was unduly deflationary, that therefore the System was in a position, in the opinion of a portion of the public at least, of resisting the recovery program, that for that reason the Board of Governors could not be motivated 
exclusively by the economic factors in the situation and disregard the psychological factors and that the subsequent reduction of reserve requirements was believed to be in the best interests of the Federal Reserve System.

Despite the ongoing recession, the Board apparently saw no economic reasons for reversing the increase in reserve requirements. Rather, it did so "in the best interests of the Federal Reserve System." 8

Following the actions announced by the President on April 14, excess reserves once again rose to high levels and, with additional gold inflows, they continued to rise (Figure 4). By the end of 1938 excess reserves had exceeded the supposedly dangerously inflationary levels that had been seen in 1935. Yields on three-month Treasury bills, which stood at 14 basis points during the week ending April 9, 1938 (the last week prior to the policy reversal), fell to 4 basis points by the end of April, and to 2 basis points by the end of the year. Likewise, yields on 3- to 5-year Treasury notes fell from 106 basis points to 83 basis points by the end of the month and to 66 basis points by the end of the year, and long-term government bond yields, which stood at 2.68 percent during the week ending April 9, fell 13 basis point by the end of the month and 20 basis by the end of the year. ${ }^{9}$

Additional monetary easing had proven possible and effective, after all. By June, 1938, the economic contraction had stopped and the incomplete economic recovery following the Great Depression was back on track once again. With additional gold inflows, and a continued passive stance by the Federal Reserve, excess reserves continued to rise and by the end of 1939 they were at nearly twice the supposedly dangerous level that had been reached four years earlier. And with the Federal Reserve no longer attempting to reverse this monetary expansion, interest rates fell even further, and the economy kept its rapid pace of expansion.

\footnotetext{
${ }^{8}$ Meltzer (2003) points out that a preliminary draft of the Board's announcement of the reduction of reserve requirements noted the presence of "ample excess reserves to meet any probable needs," which argued against the reduction in reserve requirements, and explicitly stated that "...the Board could not be motivated exclusively by the economic factors in the situation and disregard the psychological factors," as an explanation for the adopted policy reversal. This language was cut from the final draft of the Board announcement (Meltzer, 2003, p. 531, footnote 240).

${ }^{9}$ These interest rate responses to the policy reversal may appear surprisingly strong but are not unusual. Hanes (2000) provides a detailed examination of the role of the changes in excess reserves during the mid1930 s on the behavior of interest rates at various maturities. As he documents, increases in the supply of reserves during this period caused significant reductions in interest rates at longer maturities, even when the short-term rate of interest was essentially zero, and, as a result, did not reflect the underlying changes in monetary policy as it would the case under more ordinary circumstances.
} 
In addition to monetary policy, several changes in the stance of fiscal policy occured during the mid-1930s. Following the lead of analysis by the Federal Reserve (such as the study by Currie (1980, [1938]) cited earlier), some observers have attributed the fluctuations of economic activity surrounding the 1937-38 recession to fiscal factors. Since changes in fiscal policy may have potentially also contributed to the sharp swing in output during the 1937-38 recession, confirmation of the effectiveness of the swing in monetary policy in causing the swing in economic activity requires an examination of the relative role of changes in fiscal and monetary policy during the episode. Some informative decompositions along these lines have been performed by Romer (1992), in a study investigating the end of the Great Depression. Using an annual model, Romer finds that very little, if any, of the output fluctuations during the 1930s can be attributed to changes in fiscal policy. By contrast, she finds that changes in monetary policy, as measured either by changes in the growth of M1, or by changes in her estimates of ex ante real interest rates, contributed significantly to the output fluctuations during the 1930s, including during and following the 1937-38 recession.

In summary, the historical evidence suggests that the U.S. economy was not in a liquidity trap during this episode and that characterizations of monetary policy as ineffective during this period are misleading, despite the fact that short-term interest rates were close to zero for a long time. During the recovery from the Great Depression, additional monetary expansion was not permitted to occur for a time, not because it was not possible, but because the Federal Reserve believed that such expansion was not warranted. When the Federal Reserve pursued a contractionary policy based on concerns regarding the possibility of incipient inflation, the economy promptly fell into recession. And when the Federal Reserve finally allowed for monetary expansion to proceed, the economy returned to a path of rapid expansion. Short-term nominal interest rates remained very close to zero throughout, but the economy was not "caught in a liquidity trap." 


\section{A Liquidity Trap in Japan during the 1990s?}

As with the experience of the U.S. economy during the 1930s, questions regarding the possibility that the Japanese economy has perhaps been in a liquidity trap have been motivated by the fact that short-term interest rates in Japan have remained very low since 1995 (Figure 5). The recent developments in Japan are sufficiently well known that a detailed recounting of events is not necessary. ${ }^{10}$ A summary description of macroeconomic developments since 1980 in presented in Figures 6 and 7. Information is provided regarding industrial production, unemployment, stock prices and inflation, parallel to the summary description of the U.S. economy shown in Figures 2 and 3. Since the collapse in stock prices in 1989 (an event which has been frequently compared to the 1929 stock market collapse in the United States), the Japanese economy has not regained its impressive form evidenced in the strong growth and high employment of previous decades. Comparing the figures confirms that the Japanese experience of the 1990s has not been at all similar in magnitude to the economic catastrophe seen in U.S. during the Great Depression. Nonetheless, Figure 6 also confirms that throughout the 1990s the Japanese economy barely grew and that it has been in a state not drastically different from one of perpetual recession. In 1999, then-Deputy Governor Yamaguchi noted that "the Japanese economy has, if only barely, escaped deflation." As seen in the Figure 7, however, if anything, prices have moved further downward since then.

A wealth of information regarding policy decisions, their rationale and background information is also provided by the Bank of Japan and is easily accessible on its website. Useful summaries of policy decisions, and their rationale during the past several years are provided in speeches by Bank of Japan officials. ${ }^{11}$

As already noted, short-term interest rates in Japan have been very low since 1995. Since 1999 they have been very close to zero indeed. It is important to note that the reason interest rates remained higher in the period from 1995 to 1999 than in the period since then did not reflect any constraints on policy. Indeed, as then-Governor Hayami explained

\footnotetext{
${ }^{10}$ Surveys by the International Monetary Fund, as appear in the annual Article IV consultations, for example, provide a useful source.

${ }^{11}$ See for example, Hayami (1998, 1999, 2003), Ueda (1999, 2002) and Yamaguchi (1999, 2002). Particularly enlightening is the analysis of the crucial period from 1998 to the end of 2001 by Nakahara (1999, 2002).
} 
in 1998, the Bank of Japan could have eased policy further if it wished to do so (Hayami, 1998). Additional easing was not undertaken at the time, not because it was not possible, but because, according to the Bank of Japan, an evaluation of the perceived costs and benefits of such action indicated that additional easing was not warranted. The hypothesis of the possibly reduced effectiveness of further policy actions was cited as among the reasons for the inaction.

In February 1999, the Bank of Japan did decide in favor of easier monetary conditions. From February 1999 to August 2000 the Bank of Japan adopted the so-called zero-interestrate-policy (ZIRP) that was meant to imply that the overnight interest rate would be kept at a level that was "as low possible."

Since 1999 interest rates have remained at an extremely low level, with the exception of one small blip as seen in Figure 5, from August 2000 to March 2001. Similar to the events surrounding the U.S. experience in 1937 and 1938, however, this blip, and economic developments surrounding it, present a powerful illustration of the role of monetary policy actions with a near-zero nominal interest rate and help clarify that, in this case as well, the appearance of very low short-term interest rates do not represent a liquidity trap.

Aspects of the Japanese experience during the 1998-2001 period bear similarities to that of the U.S. economy during the 1935-1938 period. Most striking perhaps, is the similarity of the preemptive strike against the perception of potential inflation which prompted the tightening action in both cases. The August 11, 2000 announcement of the policy tightening provided background and details of the rationale for that action:

Over the past one year and a half, Japan's economy has substantially improved, due to such factors as support from macroeconomic policy, recovery of the world economy, diminishing concerns over the financial system, and technological innovation in the broad information and communications area. At present, Japan's economy is showing clearer signs of recovery, and this gradual upturn, led mainly by business fixed investment, is likely to continue. Under such circumstances, the downward pressure on prices stemming from weak demand has markedly receded.

Considering these developments, the Bank of Japan feels confident that Japan's economy has reached the stage where deflationary concern has been dispelled, the condition for lifting the zero interest rate policy. 
Today's decision signifies a small adjustment to the degree of monetary easing in line with the improvement of the economy, thereby contributing to long-term sustainable growth.

Even after the zero interest rate policy is terminated, monetary conditions remain largely relaxed in that the unsecured overnight call rate is still extremely low around $0.25 \%$. The Bank of Japan will conduct monetary policy in an appropriate and flexible manner to support the economic recovery consistent with price stability.

Unfortunately, in light of subsequent events, this assessment of the economic situation proved to be overly optimistic. As can be seem in Figure 6, instead of the expected improvement, industrial production collapsed following the tightening, unemployment resumed its upward trajectory and prices of both assets and goods have since fallen further from their levels at the time. The economy fell promptly back into recession. ${ }^{12}$ In response, the tightening was eventually reversed in March 2001 and, with a new operating procedure stressing an expansion in reserves (what has been called the "quantitative easing" policy), the Bank of Japan has allowed a significant accumulation of excess reserves to occur for the first time. A noteworthy development, is that although policymakers described their so called ZIRP policy as one of maintaining interest rates "as low as possible," further reductions proved not only possible in principle but in fact materialized after the 2000 tightening was reversed. And as was the case in the United States following the reversal of the 1937 tightening, the additional quantitative easing brought interest rates further down, not just at the shortest end of the term structure, but at intermediate and longer maturities as well. Figure 8 provides a graphical detail of this path of interest rates at short and intermediate maturities. The quantitative easing pursued over the past two years has been associated with an overall reduction of longer-than-overnight interest rates, even after the overnight rate reached a level of almost zero. These developments indicate that despite the near-zero short term interest rate in Japan since 1995, it would be misleading to say that the Japanese economy has been stuck in a liquidity trap.

\footnotetext{
${ }^{12}$ A provisional determination by the Economic and Social Research Institute (ESRI) dates the peak in October 2000.
} 


\section{Policy near zero interest rates}

Near-zero short-term interest rates may suggest the illusion that monetary policy has reached some imaginary limit that obscures its stance and direction. However, even when additional monetary expansion cannot be easily measured nor communicated in terms of short-term interest rates, as is the case when short-term interest rates are near-zero, there is no obvious limit to the degree of monetary expansion that a central bank can still pursue.

As long as there are assets in the economy that the central bank can purchase with money, and as long as the central bank wishes to provide additional monetary accommodation, monetary expansion can continue. ${ }^{13}$

Additional monetary expansion continues to have some bite because the prices and yields of all assets, not merely "the" short-term nominal rate of interest, jointly determine aggregate demand. Monetary expansions can influence prices of longer-term bonds and other assets, including prices of equities and foreign exchange, because none of these prices is determined solely by today's short-term rate of interest.

To better understand the role of policy on the prices of this multitude of distinct classes of assets, it is convenient to conceptually separate the effects of a monetary expansion into two parts: Effects on expectations regarding the future, and direct effects, taking expectations about the future as given. Regarding the latter, the imperfect substitutability of alternative classes of assets implies that the power to alter their supply (relative to the stock of money) through open market operations, always has a direct, though perhaps small, effect on prices. ${ }^{14}$ The effect may be "small," perhaps hardly detectable in the context of the historical influence of open market operations on relative supplies, but the size of the effect is immaterial. ${ }^{15}$ Only its presence and sign matter. Regarding the former, an increase

\footnotetext{
${ }^{13}$ To be sure, this does point to a possible artificial restriction: The central bank may lack the legal authority to purchase assets with money beyond some limit. Surely, this and other artificial restrictions of similar nature can be easily handled in a concerted effort by the central bank and other government bodies. See also Clouse et al (2000) for a discussion of technical issues relating to the implementation of monetary policy at the zero bound and related policy options.

${ }^{14}$ The importance of the presence of this effect has been emphasized in the context of the liquidity trap by Brunner and Meltzer (1968) and Meltzer (1999).

${ }^{15}$ That is to say, the degree of imperfect substitutability is, in principle, irrelevant for this point. Given the infinite potential supply of money, the only difference between "near-perfect" and more "imperfect" substitutes is the size of the money printing run and open market operation that would be required to achieve any given desired effect on a price.
} 
in the supply of money that is expected to persist in the future will result in anticipations of higher future prices, and therefore lower real interest rates at some future horizon. ${ }^{16,17}$ The key requirement for this effect to work is the ability of the central bank to credibly communicate its intentions for sustained monetary ease.

In principle, either the direct or indirect expectational effect of monetary ease could provide sufficient traction to monetary policy when the overnight rate is "stuck" at zero. In practice, however, the two effects are interconnected and should be examined together. If the central bank is credible and communicates its intentions regarding a policy of monetary ease successfully, then even a small change in current monetary conditions may have the desired effect on asset prices and real interest rates, through the force of the action and the central bank's communication on expectations. In that case, the direct effect of the monetary expansion is relatively unimportant. On the other hand, a massive expansion in the money supply may be required if the public has reason to question the durability of the central bank's actions or, more generally the factors determining the central bank's future policy. ${ }^{18}$ In that case, the direct effect of a monetary expansion becomes of greater immediate importance because it also helps the central bank improve its credibility with regard to its intention of maintaining an easier monetary policy in the future.

In practice, a central bank faced with a deflationary situation may not be in a position to assess with any accuracy its ability to influence expectations with its available communications strategy, and may therefore face substantial uncertainty about how and for how long it may need to pursue the expansionary monetary policy required to bring the economy out of a slump. Under these circumstances, the preferred mode of operations would be one that is as robust as possible to such uncertainties.

One approach is to abandon interest rate-based operating procedures under these cir-

\footnotetext{
${ }^{16}$ The role of expectational effects of this nature in the context of the zero nominal interest bound has been examined by Eggertson and Woodford (2003), Krugman (1998, 2000), Orphanides and Wieland (1998, 2000), Reifschneider and Williams (2000), Wolman (1998, forthcoming), and others.

${ }^{17}$ Note that this does not require a change in inflation expectations of the immediate future. Even if inflation expectations for the near future are extremely sticky and invariant to current policy decisions, changes in inflation expectations regarding the more distant future will still impact prices of longer-term bonds, equities and foreign currencies at present.

${ }^{18}$ For example, one could imagine a situation where a central bank pursues a form of quantitative easing but undermines its potential expectational benefits by arguing that the easing is ineffective which may lead the public to expect that the central bank will likely reverse course.
} 
cumstances, and adopt either an external anchor (with an exchange rate instrument) or a domestic monetary anchor (with a reserves or other monetary target as an instrument). ${ }^{19}$ Indeed, either approach could be successful in averting a deflationary threat, as long as it is pursued with sufficient determination. However, as Orphanides and Wieland (2000) point out, the same reasons for which the adoption of either money or the exchange rate as an instrument are generally avoided when the short-term interest rate is away from the zero bound (e.g. uncertainty regarding changes in the demand for foreign exchange or money) are present when the short-term interest rate is near zero as well. As a result, the central bank may prefer an operating procedure that continues to communicate the stance of monetary policy in terms of interest rates even when the shortest-term interest rate is near zero.

A robust operating procedure that maintains the advantages of interest-rate-based policy is simply to keep an interest rate target but adapt the targeted instrument from the overnight rate to a rate of sufficiently long maturity as required to effectively communicate the desired policy stance. One example of this approach is the operating procedure detailed in Orphanides and Wieland (2000) during the ZIRP period in Japan. ${ }^{20}$ The key sentence in Bank of Japan policy announcements during the ZIRP period read:

The Bank of Japan will flexibly provide ample funds and encourage the uncollateralized overnight interest rate to move as low as possible.

To implement this policy, the Bank of Japan adjusted the supply of reserves so as to keep the overnight rate at 2-3 basis points. Additional monetary expansion could be implemented and effectively communicated within this framework by gradually shifting the targeted interest rate that was to be "as low as possible" to instruments with maturities of e.g. 2 weeks, 4 weeks, 13 weeks and so forth, to reflect progressively greater monetary easing as needed.

More generally, and to avoid the communication difficulties associated with the definition

\footnotetext{
${ }^{19}$ See, for example, Coenen and Wieland (2003), McCallum (2000), Orphanides and Wieland (2000) and Svennson (2001).

${ }^{20}$ The procedure was originally proposed in December 1999 at a conference on Monetary Policy in a Low Inflation Environment in Tokyo. The intent was to suggest an incremental change in the operational framework that could effectively communicate additional monetary easing, if that were deemed desirable. The inflationary threat that would lead to a policy tightening a few months later was not evident at the time, at least to this writer.
} 
of "as low as possible," which, as we have seen, can be substantial when interest rates are near-zero, a central bank could specify a small positive interest rate, for example 10 or 25 basis points, as the lowest relevant target for operations. Once its overnight operating target reaches that level, the central bank could implement additional policy easings by targeting longer-term instruments, for example Treasury bills or equivalents at that positive rate. Extending the maturity of the targeted instrument in this way, effectively imposes a ceiling on interest rates at all maturities shorter than the one targeted. It thus commits the central bank to engage in open market operations and supply reserves as needed to achieve this configuration of interest rates. The procedure is robust to uncertainty because it does not require precise information about the quantity of reserves or size of open market operations that might be necessary to see the desired interest rate reductions. ${ }^{21}$

The procedure is also robust to questions regarding the credibility of the central bank. For example, with full credibility, the central bank could achieve essentially the same configuration of money market rates by either targeting an instrument with a maturity of one-year at 10 basis points or by committing to maintain the overnight rate at a comparable level (adjusting for the relevant term premium) for one year. Targeting the one-year rate directly, however, is an option that would be available for implementing policy even to a central bank with less than complete credibility.

This operating procedure does not imply nor suggest pegging long-term interest rates, as was the case in the United States in the period prior to the Federal Reserve-Treasury Accord, for example. Successful implementation of monetary easing, which could be achieved by saturating the money market through targeting rates of shorter maturities, for example one year, coupled with successful communication of the central banks' long-term inflation objective, could easily lead to upward adjustments of expectations regarding inflation and prospects for growth that might prove incompatible with the selected target on long-term bonds. Targeting long-term interest rates successfully may require more precise knowledge

\footnotetext{
${ }^{21}$ To be sure, some elements of policy would require modification. For example, the minimum term of instruments for open market operations would need to be extended. Very-short-term markets, for example the overnight money market should be expected to dry up. Surely, one would hope that the preservation of sufficient volume of operations to maintain "orderly conditions" in overnight markets, or similar considerations, would not be determining factors for setting monetary policy.
} 
of the evolution of expectations as well as the natural rate of interest than a central bank may typically possess. By contrast, an operating procedure that concentrates on targeting shorter-term interest rates, and simply extends the maturity of the targeted instrument further, as necessary for additional easing actions, can be implemented without the presumption of such accurate knowledge.

\section{Concluding Remarks}

After identifying "the mentality and ideas" of policymakers themselves, as opposed to real constraints, to be a possible crucial impediment to the policy action that could restore economic prosperity during a deflationary slump, Keynes went on to offer a "specific remedy" that he felt would be appropriate in light of the economic situation in 1930. Keynes had little doubt that with deliberate and vigorous action monetary policy could effectively control the rate of investment and avoid deflationary threats. Keynes also recognized that the precise degree of monetary expansion required might be hard to assess, and that it would importantly depend on how the central bank actions shaped expectations about the future.

The remedy should come, I suggest, from a general recognition that the rate of investment need not be beyond our control, if we are prepared to use our banking systems to effect a proper adjustment of the market-rate of interest. It might be sufficient merely to produce a general belief in the long continuance of a very low rate of short-term interest. The change, once it has begun, will feed on itself. ...

The Bank of England and the Federal Reserve Board ... should pursue bank-rate policy and open-market operations à outrance ... [t] hat is to say, they should combine to maintain a very low level of the short-term rate of interest, and buy long-dated securities ... until the short-term market is saturated. (p. 386).

Robust operating procedures in the spirit of Keynes' remedy can circumvent the appearance of a liquidity trap. While acknowledging the importance of effective communication and of the credibility of the central bank, robust procedures should remain effective even when the central bank's credibility is seen as less than perfect. One such approach is to implement additional monetary expansion by shifting the targeted interest rate to that on successively longer-term instruments, when additional monetary policy easing is warranted 
at near-zero interest rates. This approach can also be viewed as an incremental adaptation of the current operating mode of targeting an overnight rate of interest.

The prevalence of near-zero short-term interest rates may suggest the illusion of a liquidity trap. Fortunately, monetary policy need not be designed on the basis of such an illusion. 


\section{References}

Ahearne, Alan, Joseph Gagnon, Jane Haltmaier and Steve Kamin (2002). "Preventing Deflation: Lessons From Japan's Experience in the 1990s," IFDP 2002-729, June.

Bernanke, Ben S (2000). "Japanese Monetary Policy: A Case of Self-Induced Paralysis" in Mikitani and Posen (2000).

Brunner, Karl and Allan H. Meltzer (1968). "Liquidity Traps for Money, Bank Credit, and Interest Rates," Journal of Political Economy, Vol. 76, No. 1. (Jan. - Feb.), pp. 1-37.

Clouse, James, Dale Henderson, Athanasios Orphanides, David Small, and Peter Tinsley (2000). "Monetary Policy when the Nominal Short-Term Interest Rate is Zero," FEDS 2000-51, November.

Coenen, Gunter and Volker Wieland (2003). "The Zero-Interest-Rate Bound and the Role of the Exchange Rate for Monetary Policy in Japan," Journal of Monetary Economics, forthcoming.

Currie, Lauchlin (1980). "Causes of the recession" History of Political Economy, 12 (3), 316-335 (reprint of essay dated April 1, 1938.)

Eccles, Marriner (1937). "Controlling Booms and Depressions," Fortune, April, reprinted in Gayer (ed.) The Lessons of Monetary Experience, Farrar and Rinehart, New York.

Eccles, Marriner (1951). Beckoning Frontiers: Public and Personal Recollections, New York, Knopf.

Eggertson, Gauti, and Michael Woodford (2003). "The Zero Bound on Interest Rates and Optimal Monetary Policy," Brookings Papers on Economic Activity, forthcoming.

Friedman, Milton and Anna Schwartz (1963), "A Monetary History of the United States, 1867-1960".

Goodfriend, Marvin (2000), "Overcoming the Zero Bound on Interest Rate Policy," Journal of Money, Credit and Banking, 32(4, part 2), November.

Hanes, Christopher (2000), "The Liquidity Trap, the Supply of Reserves and U.S. Interest Rates in the 1930s," Manuscript.

Hayami, Masaru (1998). "Issues Regarding the Japanese Financial System and Monetary Policy," September 11.

Hayami, Masaru (1999). "Recent Monetary and Economic Conditions in Japan," article excerpted and translated by the Bank of Japan from a speech given at the Research Institute of Japan in Tokyo, March 18.

Hayami, Masaru (2003). "Towards a Sustainable Growth Path," Speech at the Keizai Club, February 25, 2003.

Keynes, John M., (1930), Treatise on Money, Volume 2. London: MacMillan.

Keynes, John M., (1936), The General Theory of Employment, Interest and Money. London: MacMillan. 
Krugman, Paul (1998), "It's Baaack: Japan's Slump and the Return of the Liquidity Trap," Brookings Papers on Economic Activity, 2:1998, 137-187.

Krugman, Paul (2000). "Thinking About the Liquidity Trap," Journal of the Japanese and International Economies 14(4), December, 221-237.

Kuttner, Kenneth N. and Adam Posen (2001). "The Great Recession: Lessons for Macroeconomic Policy from Japan," Brookings Papers on Economic Activity, 2001:2, 93-185.

Leijonhufvud, Alex, (1968). On Keynesian Economics and the Economics of Keynes: A Study in Monetary Theory, New York: Oxford University Press.

McCallum, Bennett T. (2000). "Theoretical Analysis Regarding a Zero Lower Bound on Nominal Interest Rates" Journal of Money, Credit and Banking, 32(4, part 2), November, 870-904.

Meltzer, Allan H., (1999). "Liquidity Claptrap," The International Economy, November/December, 18-23.

Meltzer, Allan H., (2003). A History of the Federal Reserve: Volume I, University of Chicago Press, Chicago.

Mikitani, Ryoichi and Adam S. Posen (2000). Japan's Financial Crises and its Parallels to U.S. Experience Institute for International Economics, Special Report 13, September.

Nakahara, Nobuyuki (1999). "Current Economic Conditions in Japan and Challenges for Monetary Policy," Speech at the Capital Markets Research Institute in Tokyo on November 1, 1999, Bank of Japan, December 14, 1999.

Nakahara, Nobuyuki (2002). "The Japanese Economy and Monetary Policy in a Deflationary Environment," Speech at the Capital Markets Research Institute in Tokyo on December 11, 2001, Bank of Japan, February 20, 2002.

Okina, Kunio (1999), "Monetary Policy Under Zero Inflation: A Response to Criticisms and Questions Regarding Monetary Policy," Bank of Japan, IMES Discussion Paper Series 99-E-20, July.

Orphanides, Athanasios (2003). "Historical Monetary Policy Analysis and the Taylor Rule." Journal of Monetary Economics, 50(5), July, 983-1022.

Orphanides, Athanasios, and Volker Wieland (1998), "Price Stability and Monetary Policy Effectiveness when Nominal Interest Rates are Bounded at Zero," Finance and Economics Discussion Series, 98-35, Board of Governors of the Federal Reserve System, June.

Orphanides, Athanasios and Volker Wieland (2000), "Efficient Monetary Policy Design near Price Stability." Journal of the Japanese and International Economies 14(4), December, 221-237.

Reifschneider, David, and John Williams (2000), "Three Lessons for Monetary Policy in a Low Inflation Era," Journal of Money, Credit and Banking, 32(4, part 2), November.

Romer, Christina D. (1992), "What Ended the Great Depression?" Journal of Economic History 52(4), 757-784, December. 
Svensson, Lars (2001). "The Zero Bound in an Open-Economy: A Foolproof Way of Escaping from a Liquidity Trap," Monetary and Economic Studies, 19, 277-312.

Temin, Peter (1976). Did Monetary Forces Cause the Great Depression? New York.

Ueda, Kazuo (1999), "The Bank of Japan's Forward Looking Approach," Remarks at the Meeting on Economic and Financial Matters in Kagoshima, July 1.

Ueda, Kazuo (2002), "Structural Problems and the Effectiveness of Monetary Policy," Based on a speech at the Meeting on Economic and Financial Matters in Maebashi City, Gunma Prefecture on April 24, 2002.

United States Congress (1935). Banking Act of 1935, Hearings before the Committee on Banking and Currency, House of Representatives, United States Government Printing Office, Washington D.C.

Wolman, Alexander S. (1998), "Staggered Price Setting and the Zero Bound on Nominal Interest Rates," Federal Reserve Bank of Richmond Economic Review, 84, 1-24, Fall.

Wolman, Alexander S. (forthcoming), "Real Implications of the Zero Bound on Nominal Interest Rates," Journal of Money, Credit and Banking.

Yamaguchi, Yutaka (1999), "Monetary Policy and Structural Policy: A Japan Perspective," Remarks prepared for a conference at the Banque de France, October 8-9, 1999.

Yamaguchi, Yutaka (2002), "Monetary Policy in a Changing Economic Environment" Remarks at a symposium sponsored by the Federal Reserve Bank of Kansas City, Jackson Hole, Wyoming, on August 30, 2002. 
Figure 1

\section{Short-Term Interest Rates}

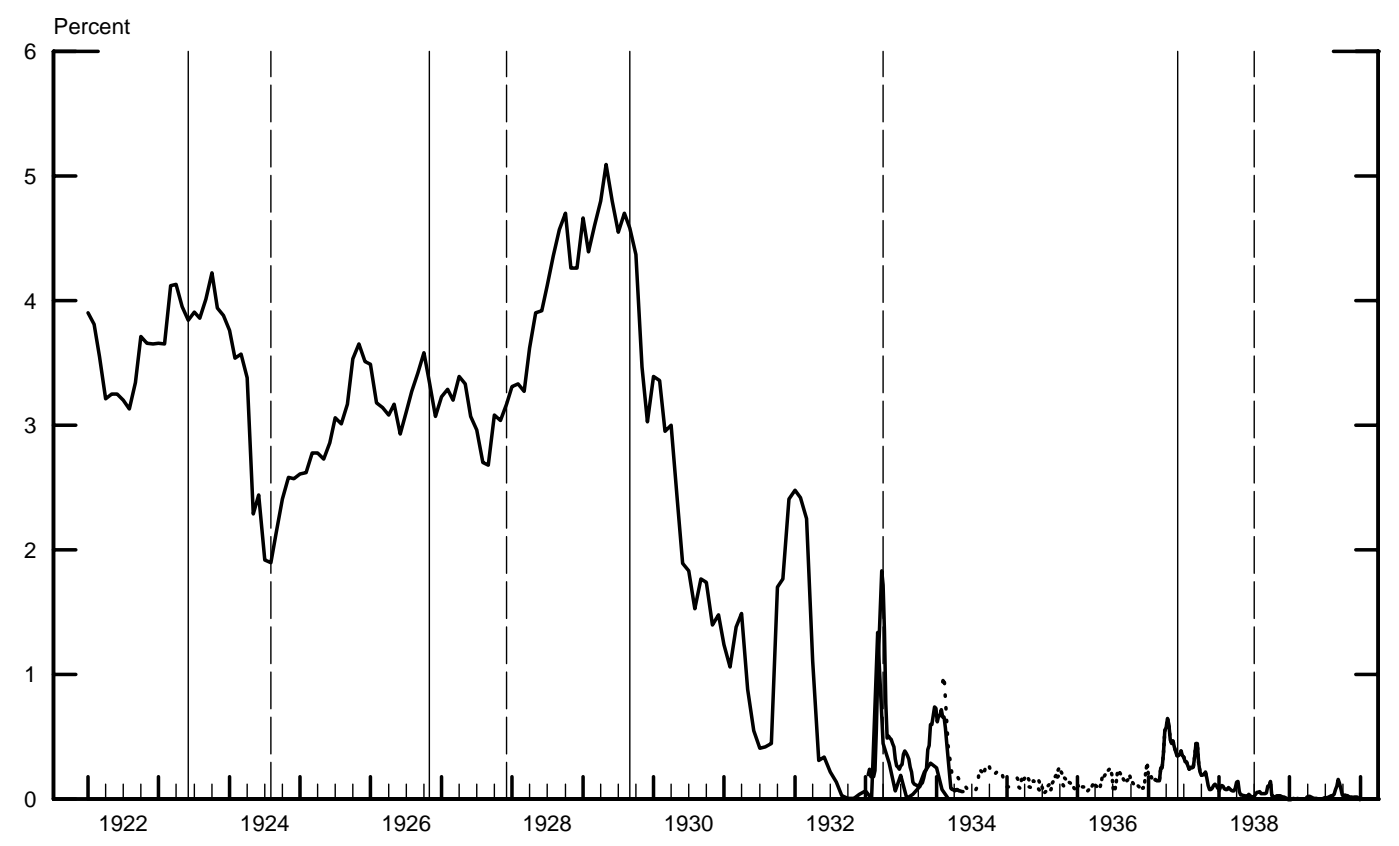

Notes: Weekly data. The solid line denotes the yield on new issues of 3-month Treasury bills or equivalents. The dotted lines (from 1934 to 1937) reflect yields on new issues of 6- and 9-month Treasury bills. Solid (dashed) vertical lines denote NBER peak (trough) dates. 
Figure 2

\section{Economic Activity in the 1920s and 1930s}

\section{Industrial Production}

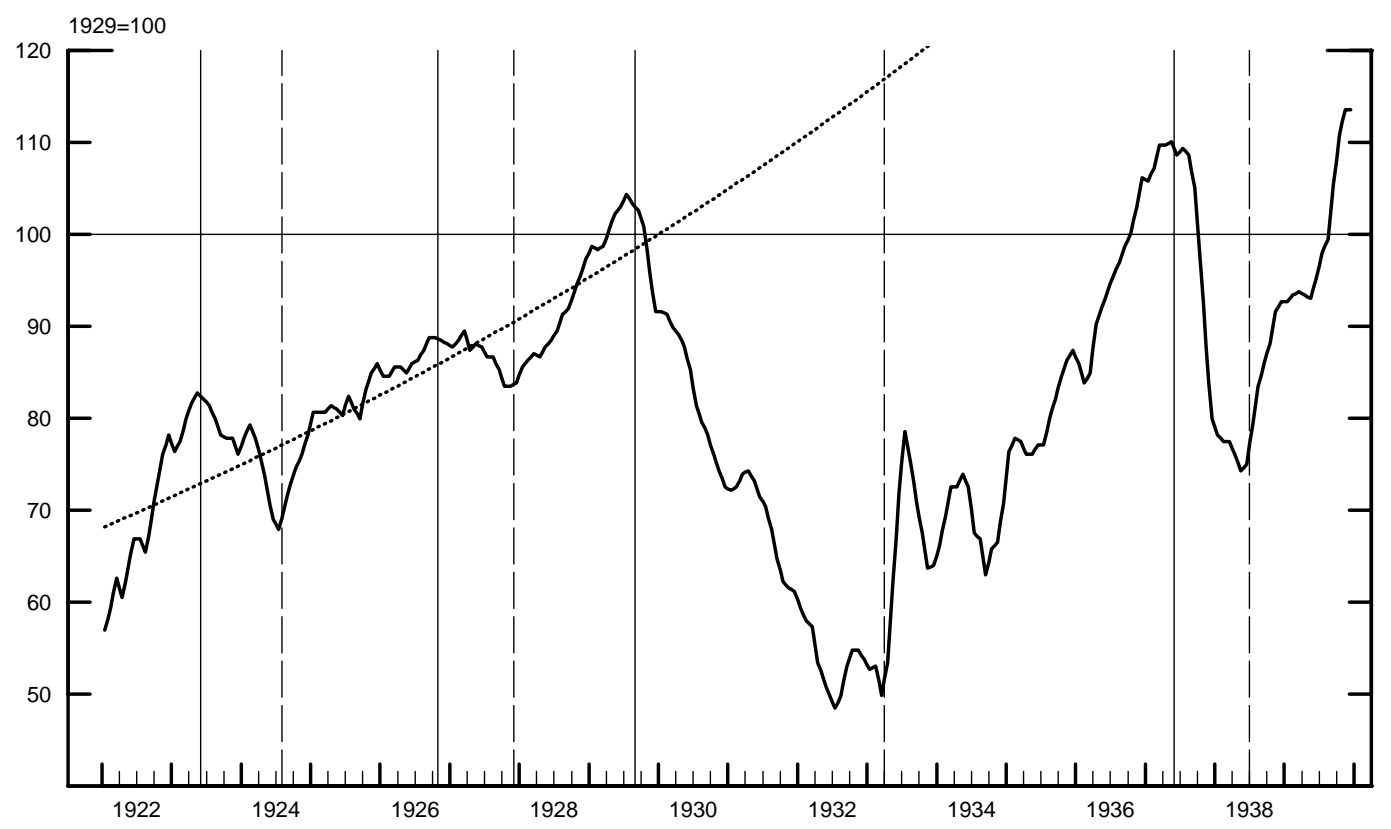

Unemployment Rate

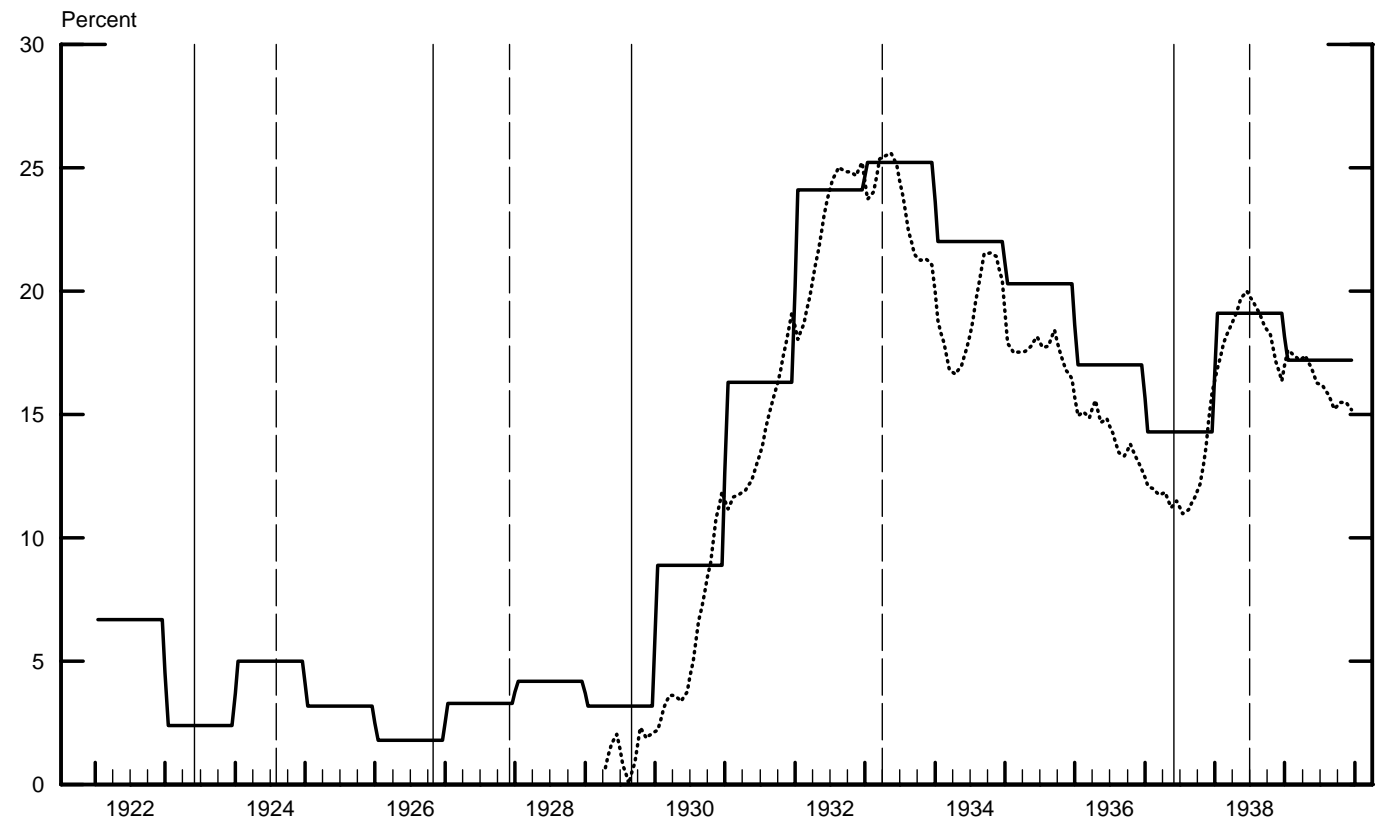

Notes: The dotted line in the top panel shows a log-linear trend fitted over the 1922-1929 period. In the bottom panel, two alternative available estimates of the unemployment rate for this period are shown, the annual series by Lebergott (solid line) and a monthly series by the National Industrial Conference Board (dotted line). Solid (dashed) vertical lines denote NBER peak (trough) dates. 
Figure 3

Prices in the 1920s and 1930s

Consumer and Producer Prices

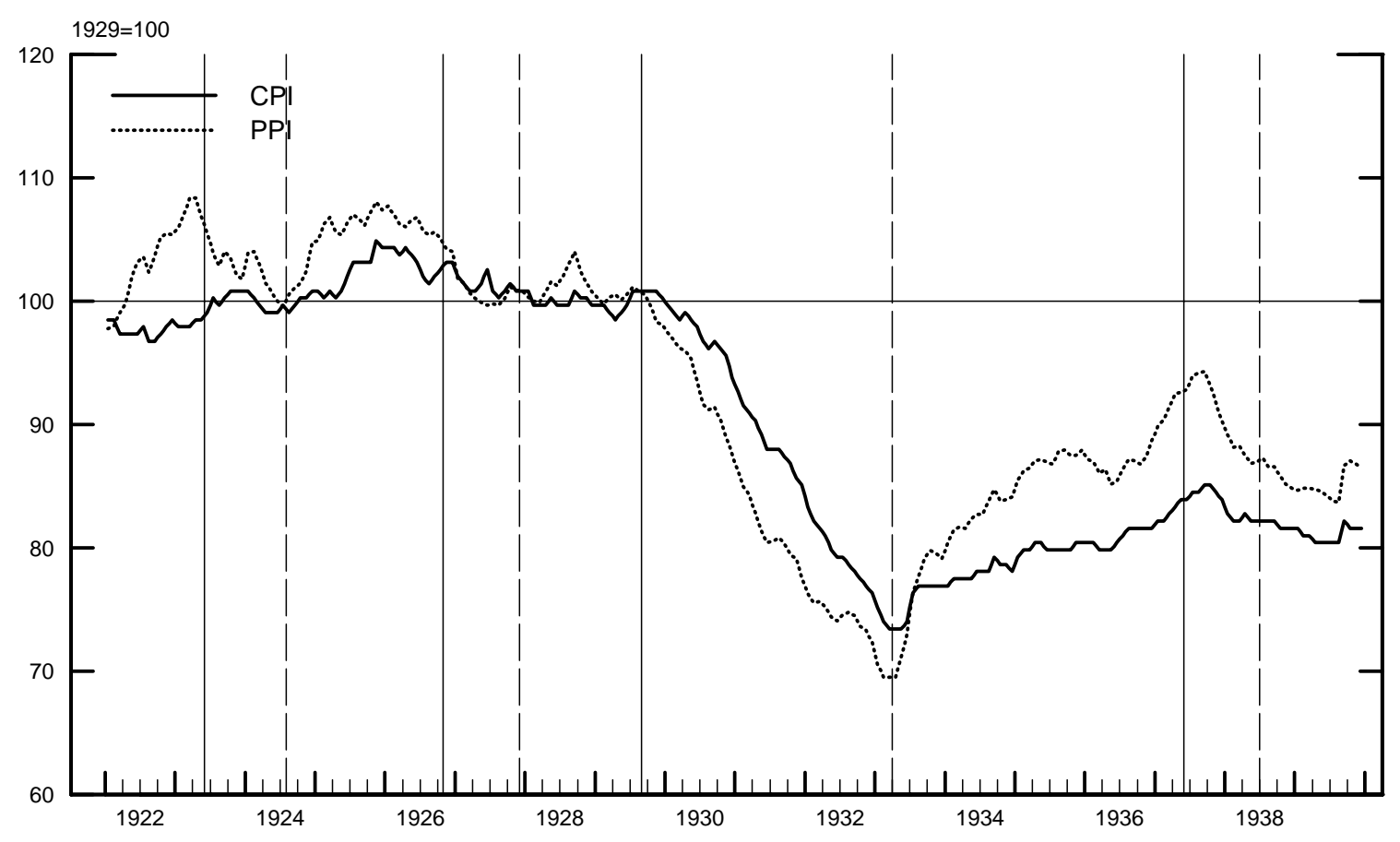

Equity Prices (Dow Jones Index)

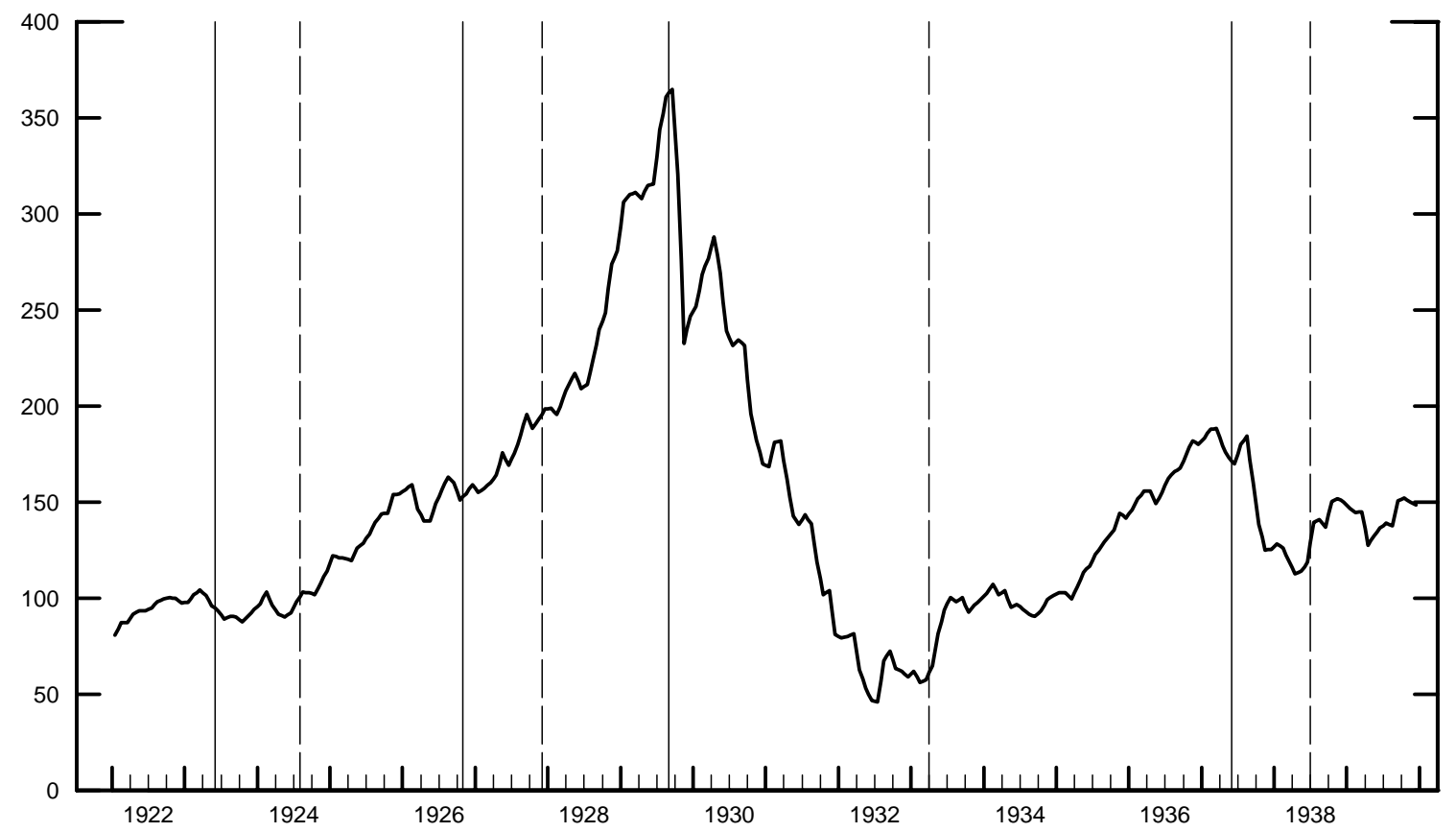

Notes: Solid (dashed) vertical lines denote NBER peak (trough) dates. 
Figure 4

\section{Excess Reserves and Treasury Bill Rates}

Treasury Bill Rates

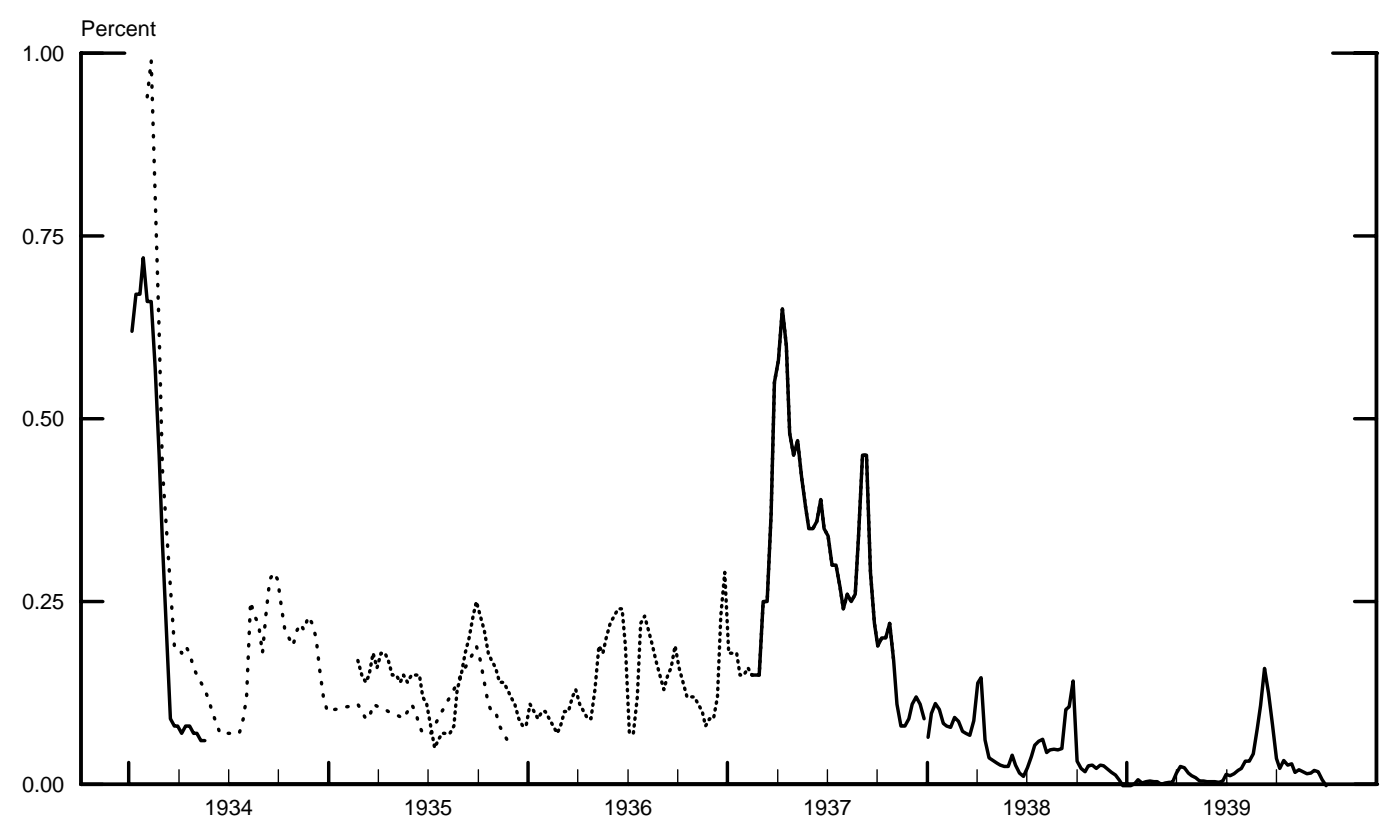

Excess Reserves

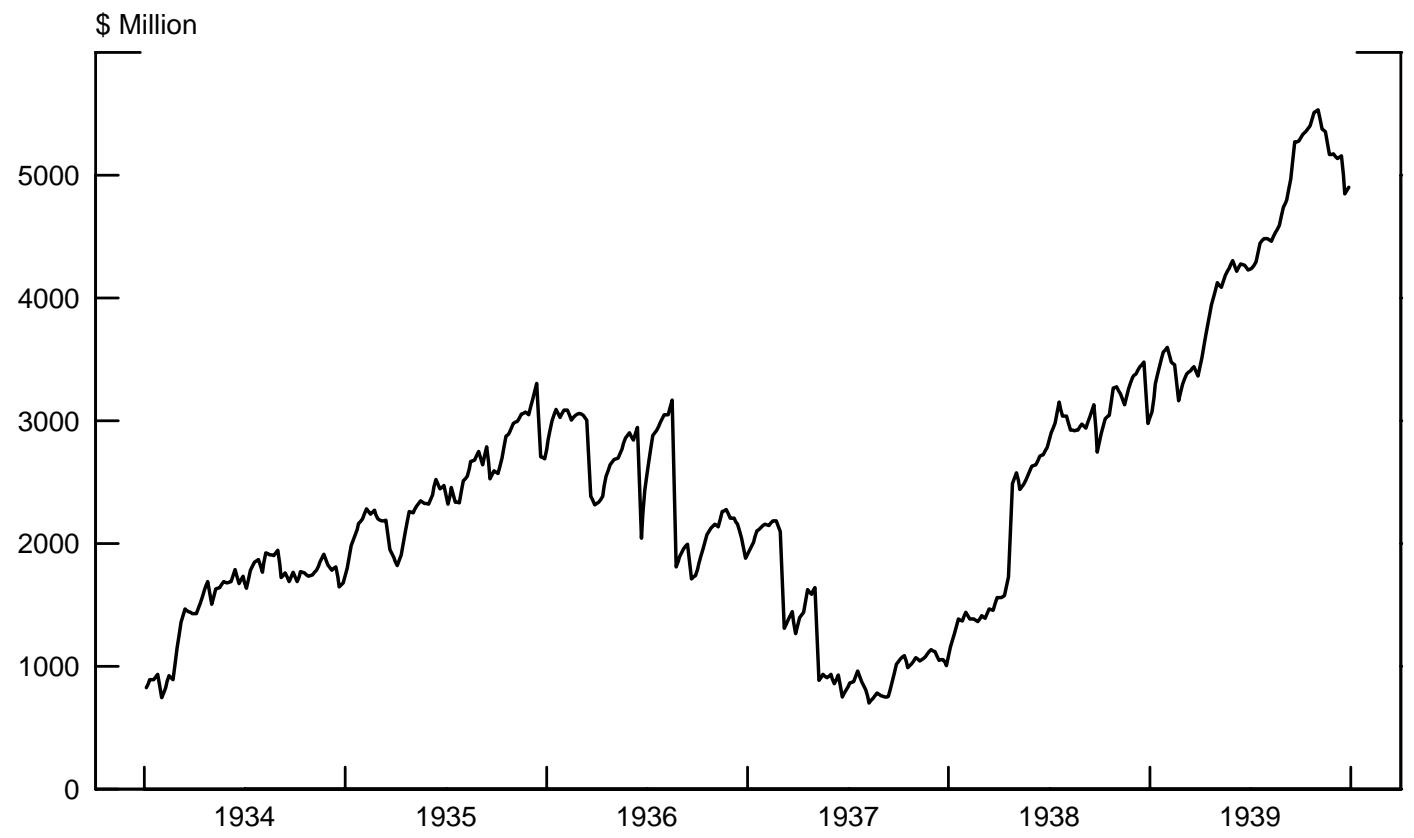

Notes: The top panel is a detail from Figure 1. See also notes to that figure. 
Figure 5

\section{Overnight Interest Rate: Japan}

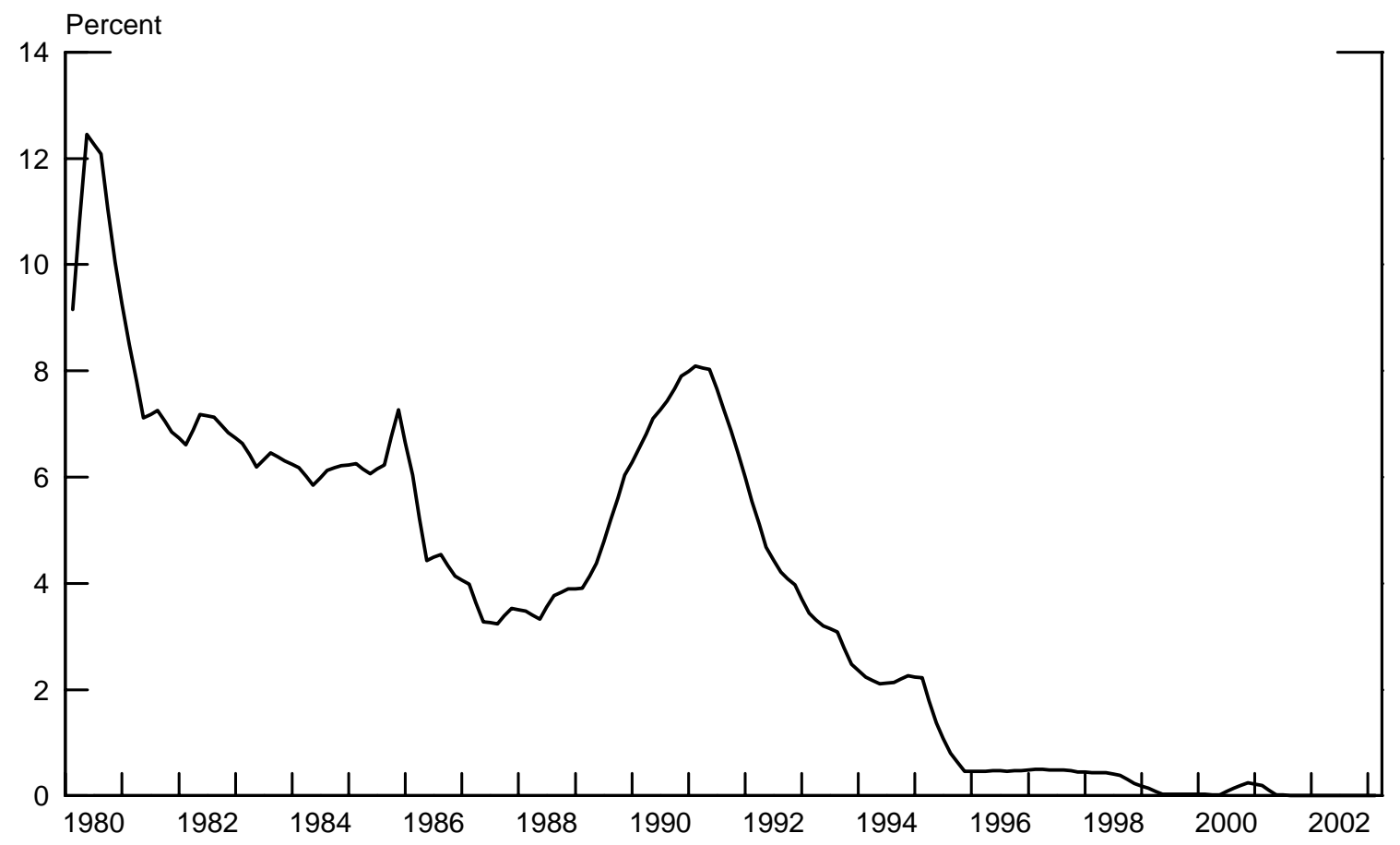


Figure 6

Economic Activity in Japan since 1980

Industrial Production

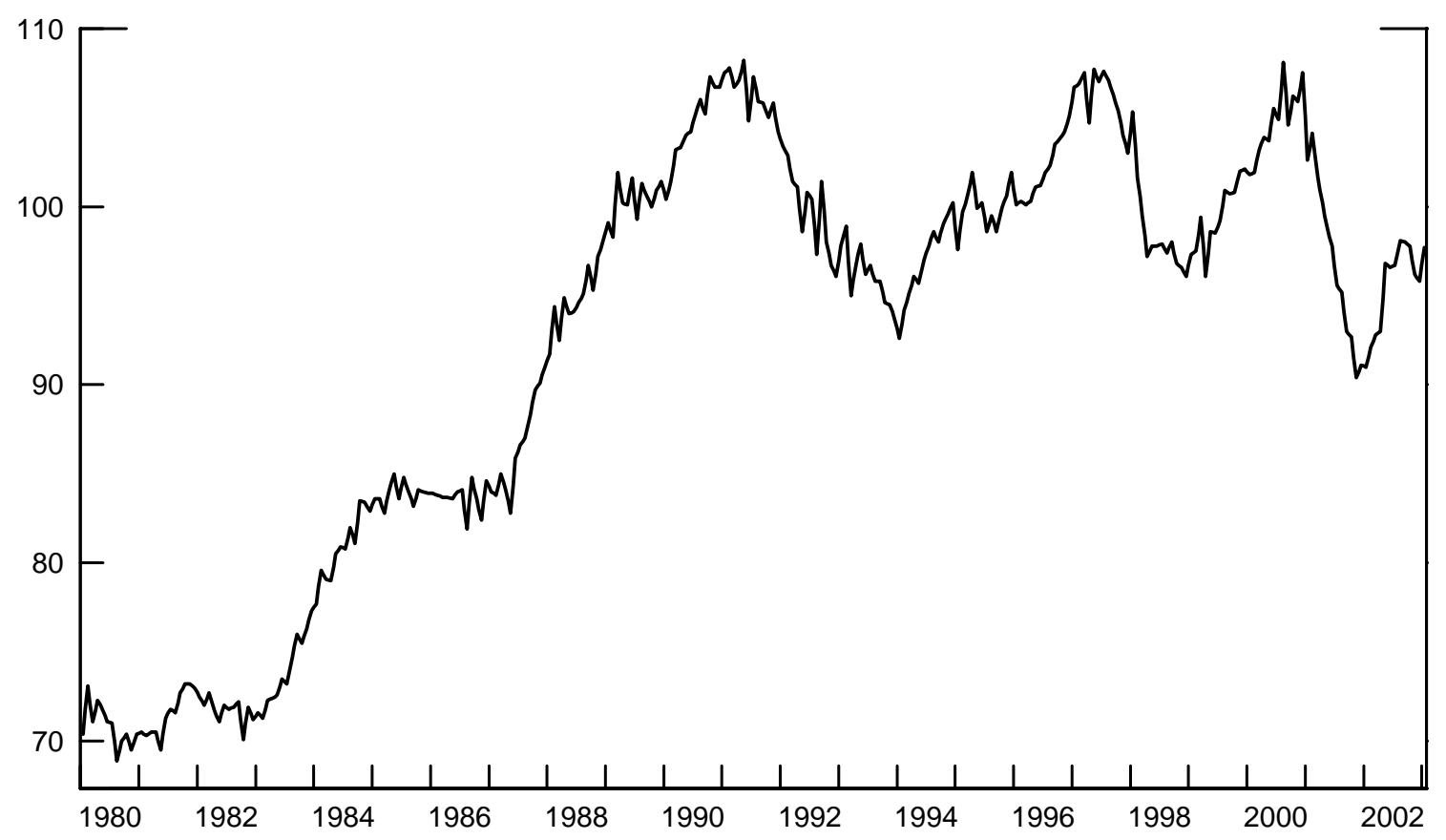

Unemployment Rate

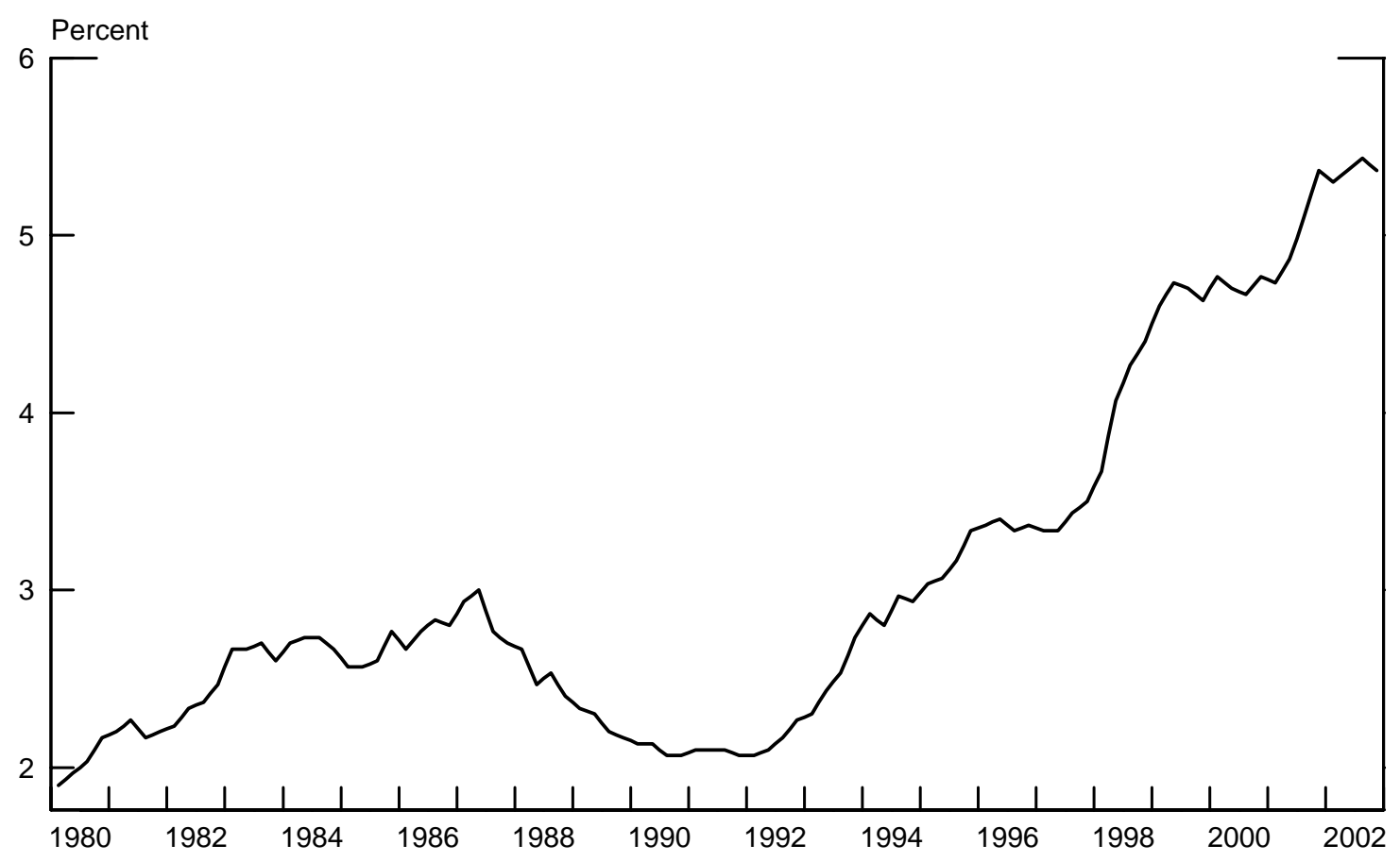


Figure 7

Inflation and Equity Prices in Japan since 1980

Inflation

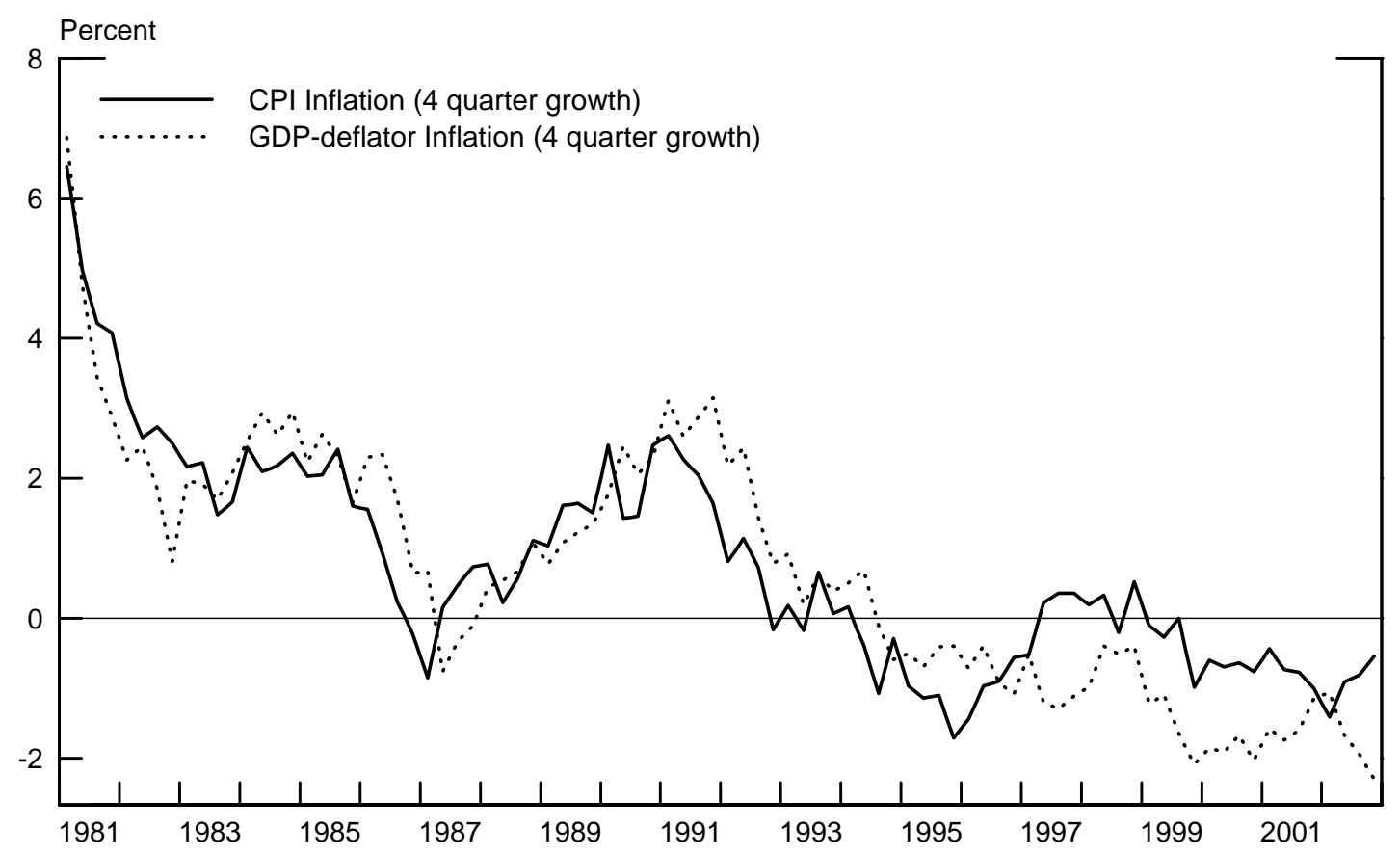

Equity Prices (Nikkei)

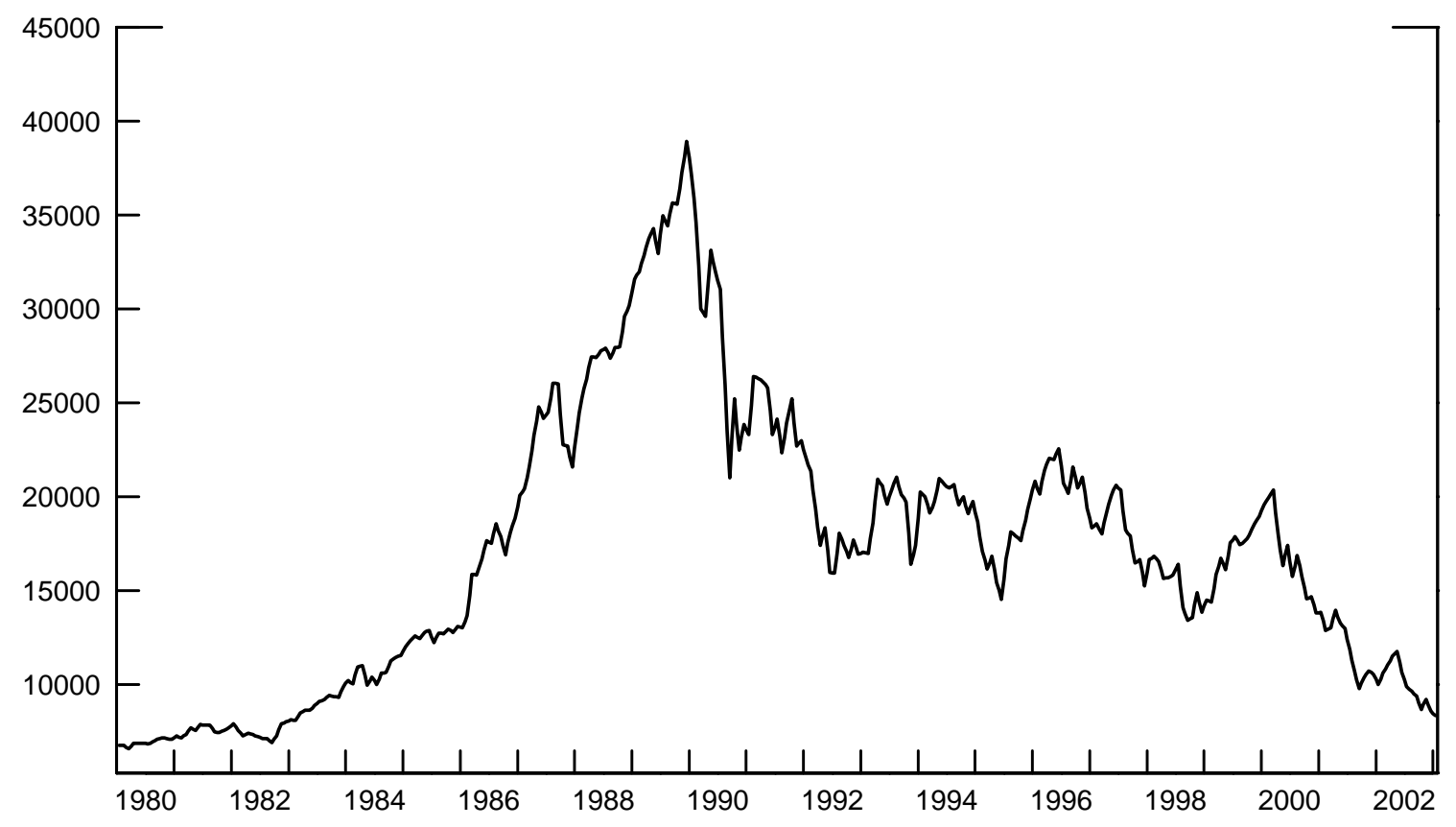


Figure 8

Interest Rates at Various Maturities in Japan since 1997
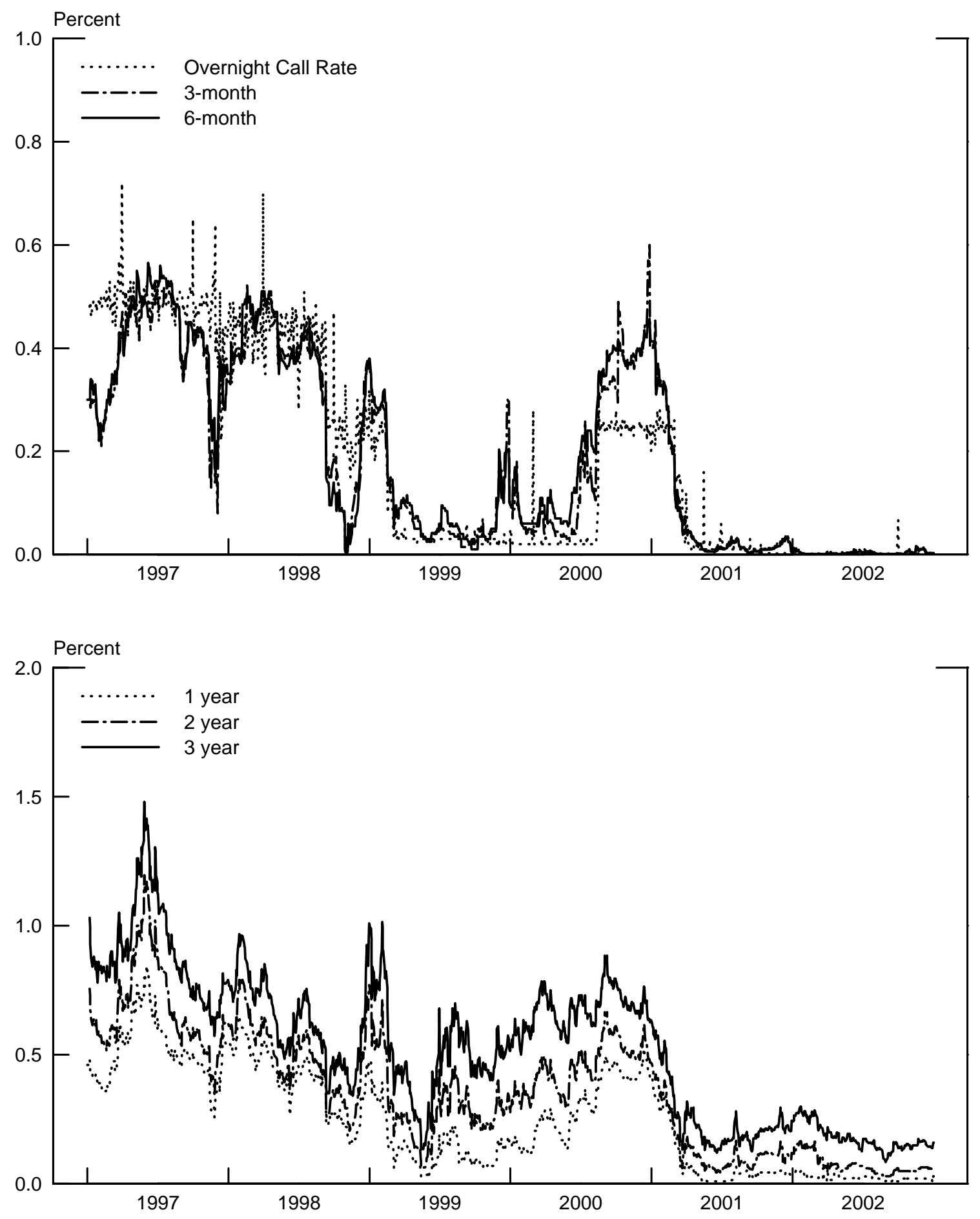